\title{
Synthesis and Fluorescent Properties of End-Functional PSt Initiated by 5-Chloromethyl-2-methoxy-benzaldehyde via ATRP
}

\author{
Qing-Feng Xu, Jian-Mei Lu, ${ }^{\dagger}$ Zhen YANG, Xue-Wei XIA, and Li-Hua Wang \\ Key Laboratory of Organic Synthesis of Jiangsu Province, School of Chemistry and Chemical Engineering, \\ Suzhou University, Henyi Road, Suzhou 215123, Jiangsu, China
}

(Received May 15, 2006; Accepted December 9, 2006; Published February 9, 2007)

\begin{abstract}
Atom transfer radical polymerization (ATRP) of styrene (St) using two initiators with similar structures, 5-chloromethyl-2-methoxy-benzaldehyde (CMMB) and 5-chloromethyl-2-hydroxyl-benzaldehyde (CMOB), $\mathrm{CuCl} / N, N, N^{\prime}, N^{\prime \prime}, N^{\prime \prime}$-pentamethyldiethyltriamine (PMDETA) as catalyst were studied in this paper. At the same reaction condition, the ATRP using CMMB was obviously accelerated, the efficiency of the initiator was higher and even could proceed at relatively lower temperature $\left(40^{\circ} \mathrm{C}\right)$, while ATRP using CMOB as initiator shows obvious slowinitiation and was under poor-control. It was speculated that, the methoxy group in CMMB has stronger electron-donor ability and avoid the formation of hydrogen bond, so that the ATRP was promoted. Furthermore, the end group of obtained PSt can also be turned into Schiff base and form polymeric complex with metal ions, which owns good film-forming ability and shows visible fluorescence. [doi:10.1295/polymj.PJ2006032]

KEY WORDS 5-Chloromethyl-2-methoxy-benzaldehyde / ATRP / Initiator / Fluorescence /
\end{abstract}

Atom transfer radical polymerization (ATRP) is one of the relatively new and versatile methods for controlled polymerizations, ${ }^{1-5}$ which allows polymers with controlled molecular weights and narrow molecular weight distributions to be prepared, and it is tolerant of a certain number of functional initiators such as block, comb and graft, star, hyperbranched and surface-anchored configurations. ${ }^{6,7}$ In particular, various optical and electronical polymers with functional groups at $\alpha$-end can be obtained using functional initiators. ${ }^{8-10}$ For example, a spirooxazine functional halo-initiator was capable of initiating an ATRP to obtain a photochromic material. ${ }^{11}$ Recently, utilizing functionalized metal complexes initiators in ATRP to obtain functional polymeric metal complexes (PMC) have begun to be reported. ${ }^{12-14}$ In our lab, one of our research efforts has focused on the design and synthesis of various metal-containing polymers with optical properties such as nonlinear optics and fluorescence. ${ }^{15-18}$ In our previous reports, a polystyrene with Schiff base at $\alpha$-end were obtained by functionalizing $\alpha$-end of the PSt obtained through ATRP using 5-chloromethyl-2-hydroxyl-benzaldehyde (CMOB) as initiator ${ }^{15,16}$ and its $\mathrm{Zn}(\mathrm{II})$ complex showed strong green fluorescence assigned to the MLCT of Zinc ion and the polymeric ligand. However, we also mentioned that this ATRP existed obvious slow-initiation and was under poor control using $\mathrm{CMOB}$ as initiator. We suspected that it may contribute to the hydrogen bond formation of CMOB. In order to better understand the initiator behavior in such a polymerization, we synthesized an analogous initiator, 5-chloromethyl-2-methoxy-benzaldehyde (CMMB) containing stronger electron donor, methoxy group, to avoid the hydrogen bond formation. As expectedly, CMMB promotes the polymerization indeed and shows higher initiation efficiency as CMOB. Furthermore, the end group of obtained PSt can also be turned into Schiff base and form polymeric complex with metal ions, which owns good film-forming ability and shows visible fluorescence.

\section{EXPERIMENTAL}

\section{Materials}

5-Chloromethyl-2-hydroxy-benzaldehyde (CMOB) was obtained by chloromethylation of salicylaldehyde. ${ }^{15}$ Light petroleum (analytical reagent, bp 60$90^{\circ} \mathrm{C}$ ), was dried with $4 \AA$ molecular sieve. Styrene (CP, Shanghai chemical Reagent Co. Ltd) was purified by extracting with $5 \%$ sodium hydroxide aqueous solution, followed by washing with deionized water and dried with magnesium sulfate anhydrous overnight, and finally distillated in vacuum. Copper(I) chloride $(\mathrm{CuCl})(\mathrm{AR}$, Shanghai zhenxin chemical Reagent Factory) was dissolved in hydrochloric acid, precipitated into a large amount of deionized water, filtered, washed with ethanol absolute, and dried in vacuum. $N, N, N^{\prime}, N^{\prime \prime}, N^{\prime \prime}$-pentamethyldiethyltriamine (PMDETA) (98\%, Jiangsu Liyang Jiangdian Chemical Factory) was dried with $4 \AA$ molecular sieve and distillated in vacuum. Cyclohexanone(AR) was dried

${ }^{\dagger}$ To whom correspondence should be addressed (E-mail: lujm@suda.edu.cn). 
with magnesium sulfate overnight and distillated in vacuum. Other agents were analytic pure and used without any purification.

\section{Synthesis of 5-Chloromethyl-2-methoxy-benzaldehyde ( $C M M B)$}

Chlorine hydride was passed into a well-stirred mixture of 2-methoxy-benzaldehyde $(8.16 \mathrm{~g}, 0.06$ $\mathrm{mol}$ ), formaldehyde $(4.90 \mathrm{~g}, 0.06 \mathrm{~mol} ; 37 \%)$, and concentrated hydrochloric acid $(50 \mathrm{~mL})$, kept at $50^{\circ} \mathrm{C}$ oil bath for $45 \mathrm{~min}$, then refluxed half an hour. When cooled to room temperature, the flesh-colored solid appeared. The solid was filtered and dissolved in ether. After dried by $\mathrm{MgSO}_{4}$, white crystals were obtained by evaporated of 75 percent ether. The rude products were recrystallized two times and colorless needles were obtained and dried under vacuum.

Purity: 95.37\%. Anal. Calcd(\%): C, 58.54; H, 4.88. Found: C, 58.67; H, 4.96. ${ }^{1} \mathrm{H}$ NMR: $3.91-3.95 \mathrm{ppm}$ $\left(-\mathrm{OCH}_{3}, 3 \mathrm{H}\right), 6.99-7.85 \mathrm{ppm}$ (phenyl protons, 3H), $10.46 \mathrm{ppm}(-\mathrm{CHO}, 1 \mathrm{H}), 4.58 \mathrm{ppm}\left(-\mathrm{CH}_{2} \mathrm{Cl}, 1 \mathrm{H}\right)$.

\section{Polymerization}

$\mathrm{CuCl}$ ( $4.8 \mathrm{mg}, 0.048 \mathrm{mmol}$ ), PMDETA $(8.3 \mathrm{mg}$, $0.048 \mathrm{mmol})$, cyclohexanone (1.05 g, $12.5 \mathrm{mmol})$, styrene $(1.00 \mathrm{~g}, 9.6 \mathrm{mmol})$, initiator CMMB (or CMOB) were mixed in a round-bottomed flask. The flask was sealed and cycled between vacuum and $\mathrm{N}_{2}$ for four times. Then the flask was sealed under $\mathrm{N}_{2}$ and placed in a preheated oil bath at a pre-determined temperature. Samples were taken at regular intervals for conversion and molecular weight analysis. The samples were dissolved in THF and precipitated into a large amount of methanol/HCl $(100 / 0.5, \mathrm{~V} / \mathrm{V})$. The precipitation was filtrated and dried under vacuum.

\section{Condensation of Aldehyde Group with o-Aminophenol} $o$-Aminophenol $(4 \mathrm{mmol})$ was added to THF (20 $\mathrm{mL}$ ) solution containing $0.1 \mathrm{mmol}$ polystyrene with aldehyde end group and refluxed for $48 \mathrm{~h}$. The sample was precipitated in a large amount of methanol, collected by filtration, dissolved in THF and precipitated in methanol for two times to remove residual $o$-aminophenol. The precipitation was finally filtrated and dried in vacuum. Whether the condensation reaction was finished can be detected by ${ }^{1} \mathrm{H}$ NMR spectrum of PSt.

\section{Preparation of Polystyrene Metal Complex (PSt-CH$-\mathrm{CH}_{2}$ MBAP-Zn)}

Polystyrene ligand $\left(2 \times 10^{-5} \mathrm{~mol}\right)$ was dissolved in DMF $(30 \mathrm{~mL}), \mathrm{Zn}(\mathrm{Ac})_{2} \cdot 2 \mathrm{H}_{2} \mathrm{O}\left(4 \times 10^{-4} \mathrm{~mol}\right)$ was added in and the mixture was stirred at room temperature. After the reaction, the mixed solution was dropped into a large mount of methanol and polymeric complex was precipitated, then filtrated, washed with deionized water and methanol respectively. The polymeric complex was soluble in common organic solvents, such as THF, DMF, $\mathrm{CH}_{2} \mathrm{Cl}_{2}$, acetone, ether, etc. ICP result: zinc content is $0.8 \%$.

\section{Characterizations}

IR spectrum was measured by Perkin-Elmer 577 FT-IR instrument ( $\mathrm{KBr}$ pellet). ${ }^{1} \mathrm{H}$ NMR was measured by INOVA $400 \mathrm{MHz}$ NMR instrument, with $\mathrm{CDCl}_{3}$ as solvent. Element analysis was obtained by Carlo Erba-MOD1106 instrument. The purity of complex was analyzed by Waters 515 HPLC. Conversion for monomer was determined by gravimetry. Molecular weights and the molecular weight distributions of polystyrene were measured using waters 1515GPC with THF as a mobile phase at $30^{\circ} \mathrm{C}$. UV-Vis spectrum was measured by Perkin-Elmer $\lambda-17$ UV-Vis instrument. Emission and excitation spectrums of polymers were carried out in DMF solvent using Edinburgh-920 fluorescence spectra photometer at room temperature. The zinc concentration was measured by the PLA-SPECI Inductively Coupled Plasma (ICP).

\section{RESULTS AND DISCUSSION}

Synthesis of PSt containing 2-methoxy-benzaldehyde as end group, PSt containing Schiff base (MBAP) as end group and its zinc complex were depicted in Scheme 1 and 2 respectively.

\section{Atom Transfer Radical Polymerization of St Initiated by $C M M B$}

According to an ideal mechanism of atom transfer radical polymerization, groups of initiator should be incorporated at one end of the polymer chain, while the other end remains a terminal halide. We firstly testified the obtained polymer by ${ }^{1} \mathrm{H}$ NMR spectrum in order to better understand the ATRP mechanism.

Figure 1 shows the ${ }^{1} \mathrm{H}$ NMR spectrum of PSt initiated by CMMB. The signal at $4.31 \mathrm{ppm}$ assigns to the methine proton of $-\mathrm{CH}_{2} \mathrm{C}(\mathrm{Ph}) \mathrm{H}-\mathrm{Cl}$ at $\omega$ end, while signals at $10.40-10.44 \mathrm{ppm}, 3.86-3.88 \mathrm{ppm}$ are attributed to the protons of $-\mathrm{CHO},-\mathrm{OCH}_{3}$ respectively. According to the ratio of proton of $-\mathrm{OCH}_{3}$ (at 3.86$3.88 \mathrm{ppm}$ ) and phenyl group from monomer (at 6.47$7.25 \mathrm{ppm}$ ), the molecular weight determined by ${ }^{1} \mathrm{H}$ NMR spectrum $M_{\mathrm{n}}(\mathrm{NMR})$ is 5100 , much close to that obtained from $\operatorname{GPC}\left(M_{\mathrm{n}}(\mathrm{GPC})=5500\right.$ and $\left.M_{\mathrm{w}} / M_{\mathrm{n}}=1.29\right)$.

Through the analysis for terminal group, it is proved that the polymerization of St initiated by CMMB is accorded with the mechanism of ATRP.

As shown in Figure 2, Ln ([M] $\left.]_{0} /[\mathrm{M}]\right)$ increases lin- 


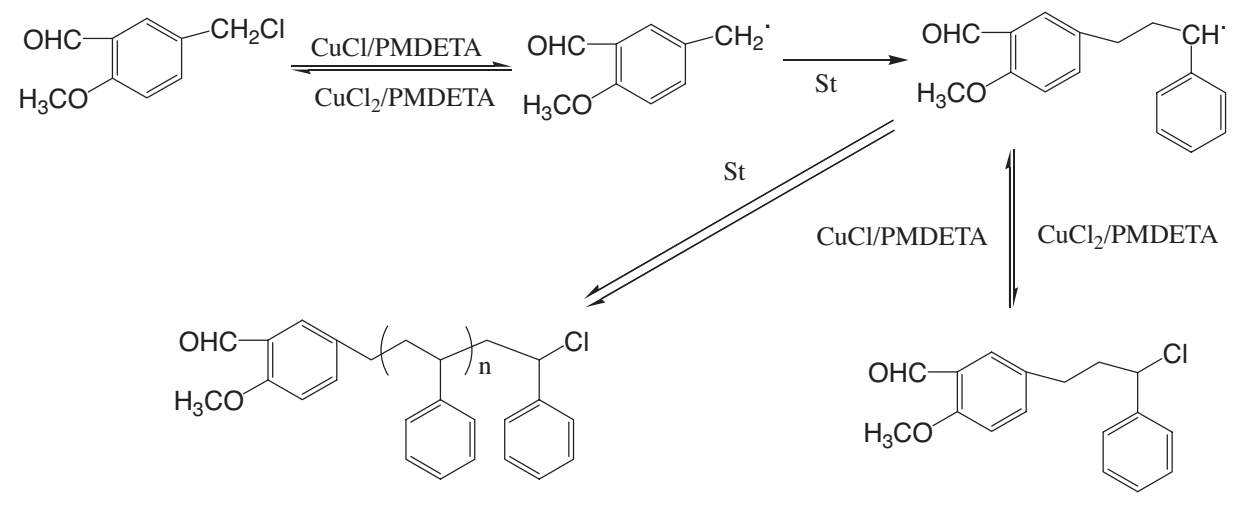

Scheme 1. ATRP of PSt initiated by CMMB.
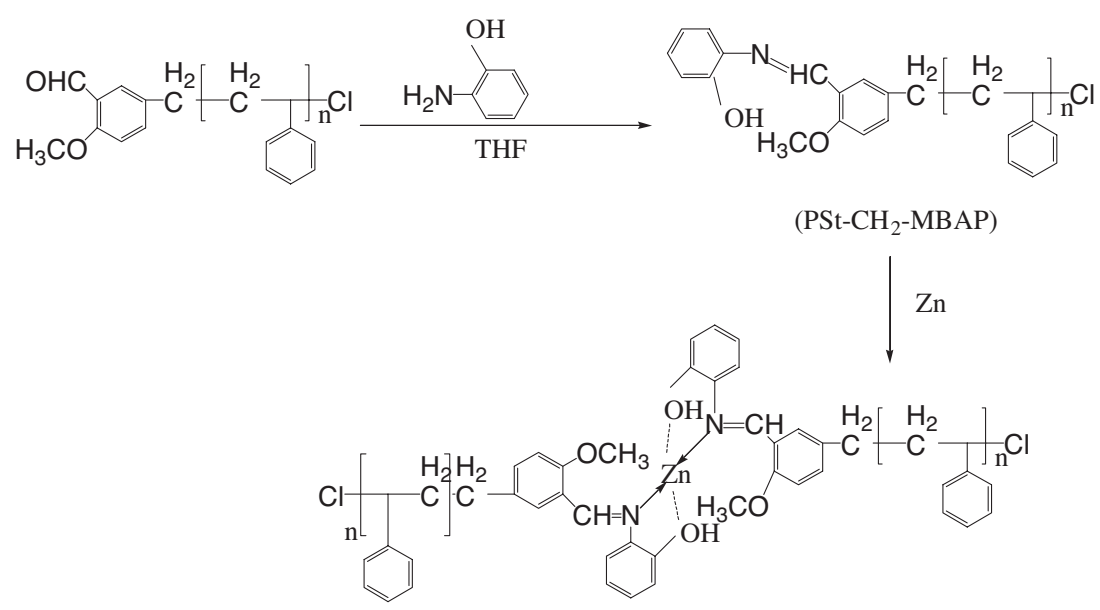

Scheme 2. Synthesis of PSt- $\mathrm{CH}_{2}-\mathrm{MBAP}$ and zinc complex.

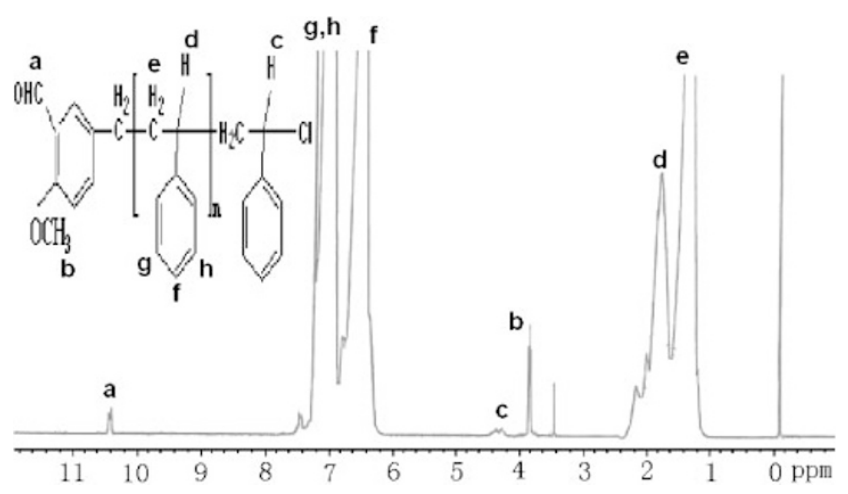

Figure 1. ${ }^{1} \mathrm{H}$ NMR spectrum of $\mathrm{PSt}-\mathrm{CH}_{2}-\mathrm{MB}$.

early with the polymerization time and passes the origin with CMMB as initiator. This indicates the polymerization is first order kinetics and the concentration of growing radical is a constant, different from the ATRP of CMOB as initiator. When using CMOB as initiator, $\operatorname{Ln}\left([\mathrm{M}]_{0} /[\mathrm{M}]\right)$ does not pass the origin, and there is an obvious induction period at the early stage of polymerization, which contributes to the slow-initiation of phenolic group because of the formation of hydrogen bond. However, when phenolic hydroxyl

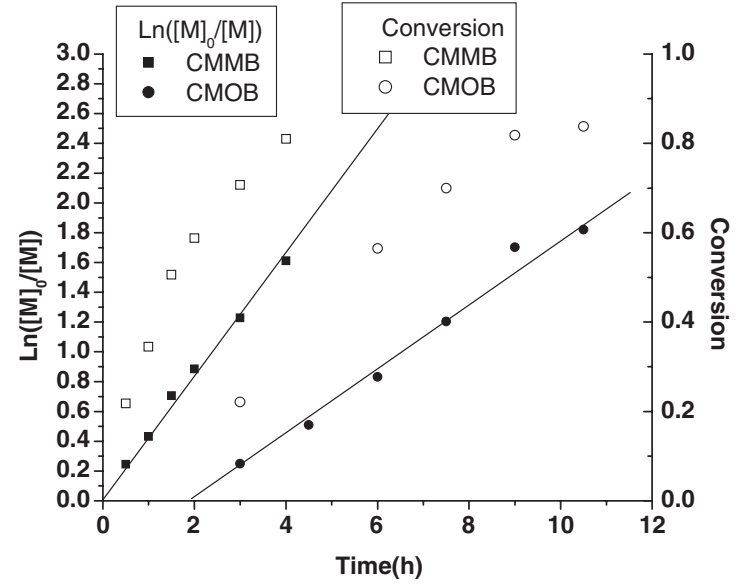

Figure 2. Kinetic plots for the polymerization of St with CMOB and CMMB as initiators in cyclohexanone solution $(50 \% \mathrm{v} / \mathrm{v})$ at $110^{\circ} \mathrm{C}$. [St]/[initiator] $/[\mathrm{CuCl}] /[\mathrm{PMDETA}]=$ 200:1:1:1.

group was replaced by methoxy group, the polymerization rate is obviously accelerated.

As shown in Figure 3, $M_{\mathrm{n}}(\mathrm{GPC})$ of PSt increases linearly with the conversation and the PDI is less than 1.5 in CMMB initiation system. It is interesting that 
Q.-F. XU et al.

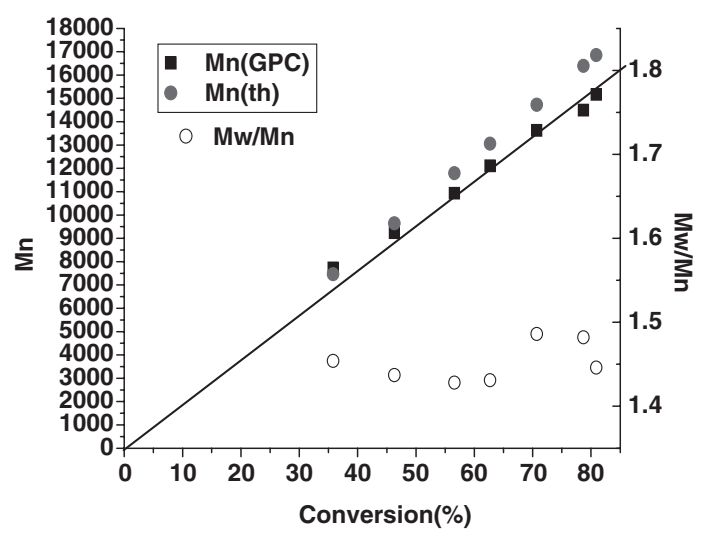

Figure 3. Evolution of $M_{\mathrm{n}}$ with conversion for the polymerization of $\mathrm{St}$ in cyclohexanone solution $(50 \% \mathrm{v} / \mathrm{v})$ at $110^{\circ} \mathrm{C}$. $[\mathrm{St}] /[\mathrm{CMMB}] /[\mathrm{CuCl}] /[\mathrm{PMDETA}]=200: 1: 1: 1$.

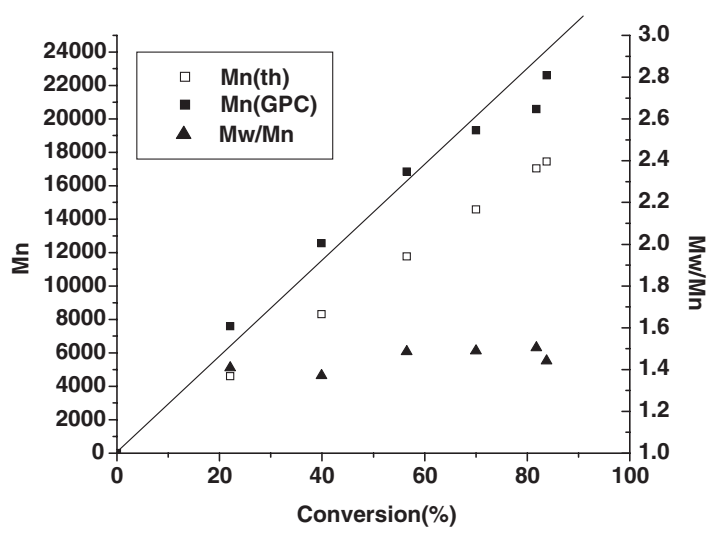

Figure 4. Evolution of $M_{\mathrm{n}}$ with conversion for the polymerization of St in cyclohexanone solution $(50 \% \mathrm{v} / \mathrm{v})$ at $110^{\circ} \mathrm{C}$. $[\mathrm{St}] /[\mathrm{CMOB}] /[\mathrm{CuCl}] /[\mathrm{PMDETA}]=200: 1: 1: 1$.

Table I. Effects of reaction temperature on percentage yield, molecular weight, initiation efficiency and polydispersity index of synthesized PSt([St]/[initiator] $/[\mathrm{CuCl}] /[\mathrm{PMDETA}]=200: 1: 1: 1)$

\begin{tabular}{crrrrrrr}
\hline $\begin{array}{c}\text { Temperature } \\
\left({ }^{\circ} \mathrm{C}\right)\end{array}$ & $\begin{array}{c}\text { Polymerization } \\
(\mathrm{h})\end{array}$ & $\begin{array}{c}\text { Conversion } \\
(\%)\end{array}$ & $M_{\mathrm{n}}(\mathrm{th})$ & $M_{\mathrm{n}}(\mathrm{GPC})$ & $M_{\mathrm{w}} / M_{\mathrm{n}}$ & $\mathrm{f}$ \\
\hline $\mathrm{CMOB}$ & 120 & 7 & 85.0 & 17700 & 22100 & 1.55 & 0.80 \\
& 110 & 7 & 60.5 & 12600 & 19200 & 1.40 & 0.65 \\
& 100 & 7 & 58.4 & 12100 & 18500 & 1.28 & 0.65 \\
& 90 & 7 & 26.9 & 5600 & 9000 & 1.25 & 0.62 \\
\hline $\mathrm{CMMB}$ & 120 & 6 & 99.0 & 20600 & 21700 & 1.58 & 1.07 \\
& 110 & 6 & 83.0 & 17200 & 15800 & 1.47 & 1.09 \\
& 100 & 6 & 67.0 & 13900 & 12900 & 1.41 & 1.08 \\
& 90 & 6 & 72.0 & 14900 & 13500 & 1.35 & 1.10 \\
& 80 & 6 & 46.0 & 9500 & 9800 & 1.30 & 0.98 \\
\hline
\end{tabular}

$M_{\mathrm{n}}(\mathrm{GPC})$ are much close to the theoretical values, so the efficiencies of the initiator (f) calculated from $M_{\mathrm{n}}(\mathrm{th}) / M_{\mathrm{n}}(\mathrm{GPC})$ are high and almost reach to 1.0. However, when using CMOB as initiator, $M_{\mathrm{n}}(\mathrm{GPC})$ are higher than their theoretical values (see Figure 4). So the ATRP of styrene is under better control by using CMMB than CMOB as initiator.

\section{Effects of Reaction Conditions}

The effects of reaction conditions such as reaction temperature, concentration of initiator and different substituting group in initiator in ATRP are discussed.

Table I shows yield, molecular weight, initiation efficiency and polydispersity index of the PSt as a function of reaction temperature. Whether using CMOB or CMMB as initiator, product yield, molecular weights $\left(M_{\mathrm{n}}\right)$ and the efficiencies all increase with the elevation of temperature. At the same temperature, the monomer conversion in CMMB initiation system is obviously higher than that in CMOB system. Moreover, due to the $M_{\mathrm{n}}(\mathrm{GPC})$ are all accorded with their theoretical values, the efficiencies of the initiator CMMB are close to 1.0 no matter how the temperature change.
Table II shows the effects of monomer to initiator mole ratio on percentage yield, molecular weight, initiation efficiency and PDI of PSt. With the concentration of initiator CMMB increasing, the polymerization is still under good control with $M_{\mathrm{n}}(\mathrm{GPC})$ decreasing and the polydispersity indexes of PSt changing little. The initiation efficiencies reduce probably due to the bimolecular termination at the early stage of polymerization. ${ }^{19}$

But, with the concentration of initiator CMOB increasing, it seems that the polymerization is under poor control because $M_{\mathrm{n}}(\mathrm{GPC})$ does not decrease, efficiencies of the initiator reduce rapidly and the PDI become widen. Compared with that of CMMB, the reducing degree of efficiencies of CMOB is obviously. These indicate that existence of phenol group is possible a main reason for the wide polydispersity index and low initiation efficiency. The result coincides with our previous report about ATRP of styrene using benzyl chloride and equal mole salicylaldehyde as initiator under the same reaction conditions ${ }^{15}$ and may be caused by the formation of hydrogen bond of CMOB.

As shown in Table III, the polymerization of St initiated by CMMB can proceed with the high initiation 
Table II. Effects of monomer to initiator mole ratio on percentage yield, molecular weight, initiation efficiency and polydispersity index of synthesized $\mathrm{PSt}\left([\right.$ initiator $] /[\mathrm{CuCl}] /[\mathrm{PMDETA}]=1: 1: 1$, at $\left.110^{\circ} \mathrm{C}\right)$

\begin{tabular}{cccccccc}
\hline \multicolumn{2}{c}{ St/initiator } & $\begin{array}{c}\text { Polymerization } \\
(\mathrm{h})\end{array}$ & $\begin{array}{c}\text { Conversion } \\
(\%)\end{array}$ & $M_{\mathrm{n}}(\mathrm{th})$ & $M_{\mathrm{n}}(\mathrm{GPC})$ & $M_{\mathrm{w}} / M_{\mathrm{n}}$ & $\mathrm{f}$ \\
\hline CMOB & $200: 1$ & 7 & 58.4 & 12100 & 18500 & 1.28 & 0.66 \\
& $100: 1$ & 7 & 61.3 & 6300 & 18600 & 1.32 & 0.34 \\
& $200: 3$ & 7 & 72.5 & 5000 & 19700 & 1.45 & 0.26 \\
& $200: 5$ & 7 & 50.3 & 2000 & 26600 & 1.54 & 0.08 \\
\hline CMMB & $200: 1$ & 6 & 83.0 & 17200 & 15800 & 1.47 & 1.09 \\
& $100: 1$ & 6 & 93.0 & 9600 & 11200 & 1.42 & 0.83 \\
& $200: 3$ & 6 & 95.0 & 6500 & 8500 & 1.37 & 0.71 \\
& $200: 5$ & 6 & 98.0 & 4000 & 6500 & 1.31 & 0.58 \\
\hline
\end{tabular}

Table III. Effects of reaction temperature on percentage yield, molecular weight, initiation efficiency and polydispersity index of synthesized PSt([St]/[CMMB]/[CuCl] $/[\mathrm{PMDETA}]=200: 1: 1: 1)$

\begin{tabular}{cccccccc}
\hline $\begin{array}{c}\text { Temperature } \\
\left({ }^{\circ} \mathrm{C}\right)\end{array}$ & $\begin{array}{c}\text { Polymerization } \\
\text { time }(\mathrm{h})\end{array}$ & $\begin{array}{c}\text { Conversion } \\
(\%)\end{array}$ & $M_{\mathrm{n}}(\mathrm{th})$ & $M_{\mathrm{n}}(\mathrm{GPC})$ & $M_{\mathrm{w}} / M_{\mathrm{n}}$ & $\mathrm{f}$ \\
\hline $\mathrm{CMMB}$ & 70 & 12 & 51.0 & 10600 & 10400 & 1.43 & 1.02 \\
& 60 & 12 & 55.0 & 11400 & 8800 & 1.44 & 1.30 \\
& 50 & 12 & 34.6 & 7200 & 8400 & 1.56 & 0.86 \\
& 40 & 12 & 32.2 & 6700 & 8900 & 1.59 & 0.75 \\
\hline
\end{tabular}

efficiencies when temperature decreases from 70 to $40^{\circ} \mathrm{C}$ but the polydispersity index expands slightly (less than 1.5). However, the similar polymerization can not proceed by using CMOB as initiator.

Two kinds of initiator have the similar structures which were composed by one electron withdrawing group (aldehyde group) and one electron donor group, in which the electron donor group is methoxy group in CMMB and phenol group in CMOB, but their initiation efficiency is obviously different. Compared both initiators, CMMB with stronger electron donor group has better initiation behavior while phenol group in CMOB with formation of hydrogen bond shows slow-initiation of ATRP and ATRP is under poor control which was proved by the low polymerization rate, the long induction period at the early stage and the low initiation efficiency.

\section{Characterizations of Metal Complex (PSt-CH$-\mathrm{CH}_{2}$ MBAP-Zn) and Fluorescent Property}

The PSt with methanoxy-benzaldehyde end group is reacted with $o$-aminophenol to afford polymeric ligand, PSt containing Schiff base as end group, PSt$\mathrm{CH}_{2}$-MBAP. The new polymer and its zinc complex were characterized and their fluorescence was also studied.

\section{Characterizations of PSt Ligand (PSt- $\mathrm{CH}_{2}-\mathrm{MBAP}$ )}

According to the ${ }^{1} \mathrm{H}$ NMR spectrum of $\mathrm{PSt}-\mathrm{CH}_{2}-$ MBAP, the signal at $10.40 \mathrm{ppm}$ decreases greatly and new signal at $7.79 \mathrm{ppm}$ appears which assign to the methine proton of $-\mathrm{CH}=\mathrm{N}-$. As shown in the

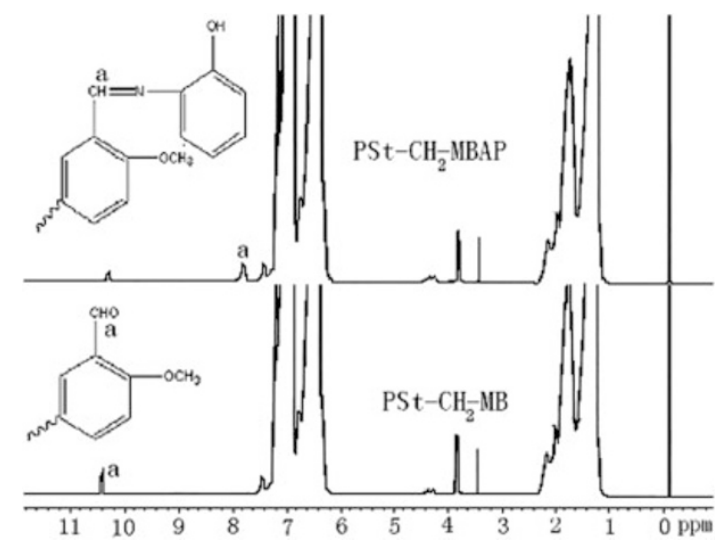

Figure 5. ${ }^{1} \mathrm{H}$ NMR spectra of $\mathrm{PSt}-\mathrm{CH}_{2}-\mathrm{MB}$ and $\mathrm{PSt}-\mathrm{CH}_{2}-$ $\operatorname{MBAP}\left(M_{\mathrm{n}}(\mathrm{GPC})=5500\right.$, PDI $\left.=1.36\right)$.

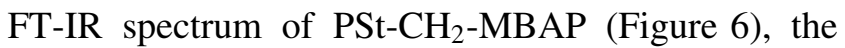
$v(\mathrm{C}=\mathrm{O})$ band at $1683 \mathrm{~cm}^{-1}$ disappears and the absorption band of the $v(\mathrm{C}=\mathrm{N})$ bond is observed at $1667 \mathrm{~cm}^{-1}$. Therefore, the end group of PSt is proved to 2-[2-Methoxy-polystyryl-Benzylidene]-Amino]phenol (Scheme 2).

\section{Characterizations of Metal Complex Polystyrene (PSt-CH$-\mathrm{MBAP}-\mathrm{Zn}$ )}

The IR spectra of polystyrene ligand and its $\mathrm{Zn}$ (II) complex are shown in Figure 6. The band at $1667 \mathrm{~cm}^{-1}(v(\mathrm{C}=\mathrm{N}))$ and $3450 \mathrm{~cm}^{-1}(v(-\mathrm{OH}))$ shift to $1660 \mathrm{~cm}^{-1}$ and $3442 \mathrm{~cm}^{-1}$ respectively. These indicate that the $-\mathrm{CH}=\mathrm{N},-\mathrm{OH}$ are coordinated with the $\mathrm{Zn}(\mathrm{II}){ }^{16,20,21}$ 


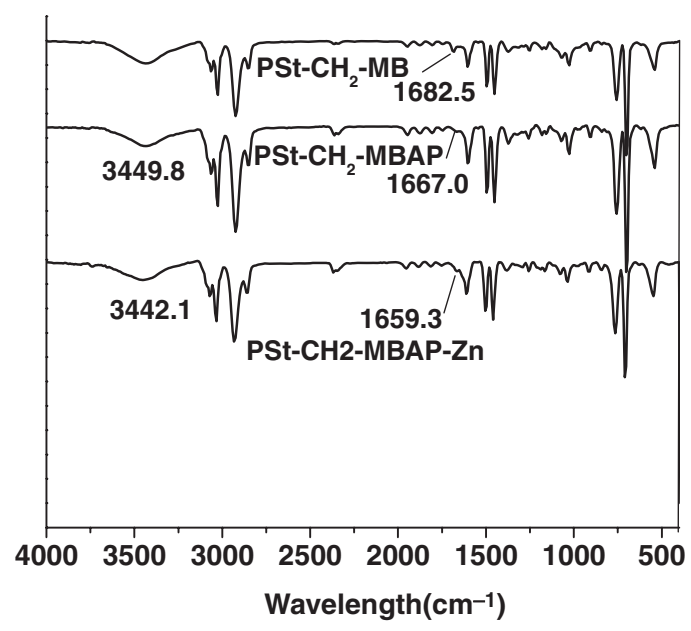

Figure 6. IR spectra of $\mathrm{PSt}-\mathrm{CH}_{2}-\mathrm{MB}, \mathrm{PSt}-\mathrm{CH}_{2}-\mathrm{MBAP}$ and PSt- $\mathrm{CH}_{2}-\mathrm{MBAP}-\mathrm{Zn}$.

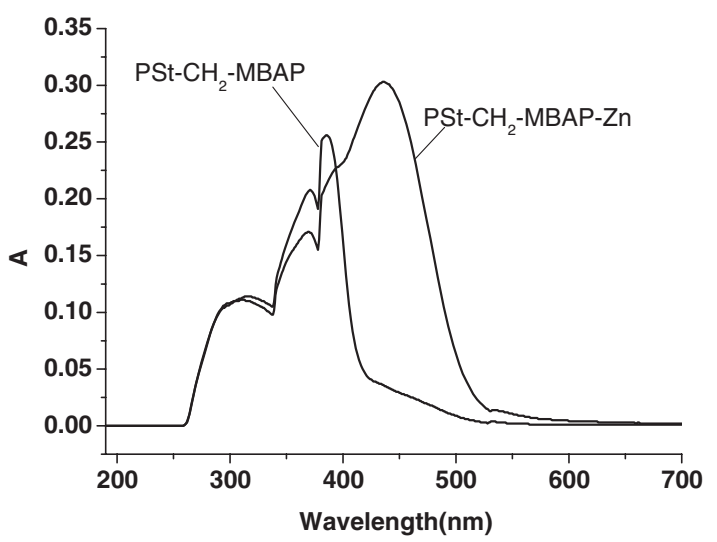

Figure 7. UV-Vis spectra of $\mathrm{PSt}-\mathrm{CH}_{2}-\mathrm{MBAP}$ and $\mathrm{PSt}-\mathrm{CH}_{2}-$ MBAP-Zn.

The UV-Vis spectra of polystyrene ligand and its $\mathrm{Zn}$ (II) complex are shown in Figure 7. The $\pi-\pi^{*}$ transition occurs at $310,375,390 \mathrm{~nm}$ for the pure ligand, PSt-MBAP. When coordinated with Zn(II), the band at $390 \mathrm{~nm}$ disappears and a new band at $425 \mathrm{~nm}$ appears, which can be assigned to the charge transfers between central zinc atom and coordinated atoms. ${ }^{16}$

\section{Fluorescent Property of Metal Complex Polystyrene}

The fluorescent emission spectra of $\mathrm{PSt}-\mathrm{CH}_{2}-$ MBAP and PSt- $\mathrm{CH}_{2}-\mathrm{MBAP}-\mathrm{Zn}$ are shown in Figure 8. The main emission bands at $380 \mathrm{~nm}$ for PSt- $\mathrm{CH}_{2}-\mathrm{MBAP}-\mathrm{Zn}$ and $410 \mathrm{~nm}$ for PSt- $\mathrm{CH}_{2}-\mathrm{MBAP}$ are assigned to the polymeric ligand-centered with $\lambda_{\mathrm{ex}}=330 \mathrm{~nm}$. The obvious blue-shifted and the stronger intensity of emission of PSt- $\mathrm{CH}_{2}-\mathrm{MBAP}-\mathrm{Zn}$ can be probably caused by the formation of interaction of $\mathrm{N}-\mathrm{Zn}$ and $\mathrm{O}-\mathrm{Zn}$, which changes the emission energy of the polymeric ligand by the lowering of the energy gap between $\pi$ and $\pi^{*}$ owing to the enlarged conjugation and enhance of electron flow. In addition,

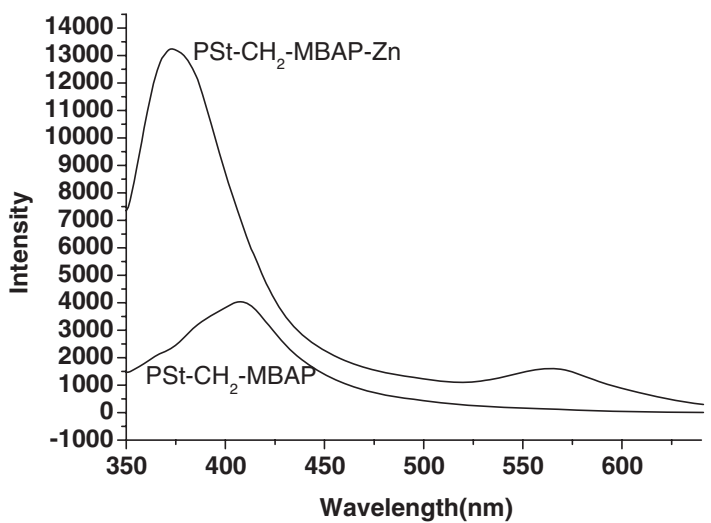

Figure 8. Emission spectra of $\mathrm{PSt}-\mathrm{CH}_{2}-\mathrm{MBAP}$, PSt- $\mathrm{CH}_{2}$ MBAP-Zn in DMF $\left(1.0 \times 10^{-4} \mathrm{~mol} / \mathrm{L}\right)$ with $\lambda_{\mathrm{ex}}=330 \mathrm{~nm}$ $\left(M_{\mathrm{n}}(\mathrm{GPC})=5500, \mathrm{PDI}=1.36\right)$.

there's a small side-band at $570 \mathrm{~nm}$ which may be assigned to the MLCT of zinc and ligand, but the intensity of emission band is much weaker than that of PSt$\mathrm{CH}_{2}$-SMOA-Zn. ${ }^{16}$ It's probably caused by the weak coordination of zinc and hydroxy group in complex PSt- $\mathrm{CH}_{2}-\mathrm{MBAP}-\mathrm{Zn}$, which may result in the decrease of electron flow between metal ion and the ligand.

\section{CONCLUSION}

The polymerization of St using 5-chloromethyl-2methoxy-benzaldehyde (CMMB) as initiator, $\mathrm{CuCl}$ as catalyst and PMDETA as ligand accorded with atom transfer radical polymerization with the high initiation efficiency. At the same polymerization condition, CMMB with stronger electron donor group (methoxy group) has better initiation behavior, and ATRP is under well control, while the similar initiator, 5-chloromethyl-2-hydroxy-benzaldehyde (CMOB) shows obvious slow-initiation and was under poor control because of the formation of hydrogen bond. Therefore, CMMB was considered as a better initiator for ATRP than CMOB.

In addition, when the aldehyde group in CMMB was turned into Schiff base and coordinated with $\mathrm{Zn}(\mathrm{II})$, the fluorescent emission of polymer $\mathrm{PSt}-\mathrm{CH}_{2}-$ MBAP was strengthened while the coordination didn't improve the intensity of emission of zinc ions obviously. The further study of designing new initiator which can both improve the initiation of polymerization and the optical property of polymer is ongoing in our lab.

Acknowledgment. This work was supported by National Nature Science foundation of China (20571054 and 20476066), the NSF of Jiangsu Province (BK2005031) and Project of high technology of Jiangsu Province (BG2005021). 


\section{REFERENCES}

1. F. J. Xu, E. T. Kang, and K. G. Neoh, Macromolecules, 38, 1573 (2005).

2. A. E. Harrak, G. Carrot, J. Oberdisse, C. Eychenne-Baron, and F. Boue, Macromolecules, 37, 6376 (2004).

3. M. Li, N. M. Jahed, K. Min, and K. Matyjaszewski, Macromolecules, 37, 2434 (2004).

4. R. M. Johnson and C. L. Fraser, Macromolecules, 37, 2718 (2004).

5. L. Cui, X. Tong, X. H. Yan, G. J. Liu, and Y. Zhao, Macromolecules, 37, 7097 (2004).

6. C. Y. Hong, Y. Z. You, D. Wu, Y. Liu, and C. Y. Pan, Macromolecules, 38, 2606 (2005).

7. G. Zhai, E. T. Kang, and K. G. Neoh, Macromolecules, 37, 7240 (2004).

8. B. Moon, T. R. Hoye, and C. W. Macosko, Polymer, 43, 5501 (2002).

9. N. P. Tzanetos and J. K. Kallitsis, Chem. Mater., 16, 2648 (2004).

10. M. Erdogan, Y. Hepuzer, I. Cianga, I. Yagc, and O. Pekcan, J. Phys. Chem. A, 107, 8363 (2003).
11. G. K. Such, R. A. Evans, and T. P. Davis, Macromolecules, 37, 9664 (2004).

12. A. Farah and W. J. Pietro, Inorg. Chim. Acta, 357, 3813 (2004).

13. R. M. Johnson, P. S. Corbin, C. Ng, and C. L. Fraser, Macromolecules, 33, 7404 (2000).

14. L. Viau, S. Bidault, O. Maury, S. Brasselet, I. Ledoux, J. Zyss, E. Ishow, K. Nakatani, and H. L. Bozec, J. Am. Chem. Soc., 126, 8386 (2004).

15. Z. Yang, J. M. Lu, S. C. Yao, and L. H. Wang, J. Macromol. Sci., Part A: Pure Appl. Chem., 41, 1105 (2004).

16. Z. Yang, J. M. Lu, and L. H. Wang, Polym. Bull., 53, 249 (2005).

17. J. M. Lu, H. Li, X. W. Xia, S. C. Yao, and X. L. Zhu, Polym. Bull., 51, 327 (2004).

18. X. W. Xia, J. M. Lu, H. Li, S. C. Yao, and L. H. Wang, Opt. Mater., 27, 1350 (2005).

19. T. Ando, M. Kamigaito, and M. Sawamoto, Macromolecules, 30, 4507 (1997).

20. N. S. Navaneetham, R. Kalyanasundaram, and S. Soundarajan, Inorg. Chim. Acta, 110, 169 (1985).

21. K. Ueno and A. E. Martell, J. Phys. Chem., 59, 988 (1955). 